\title{
An analysis of high-temperature nuclear reactor coupled with gas turbine combined cycle
}

\author{
Marek Jaszczur ${ }^{1 *}$, Michat Dudek ${ }^{1}$, Tomasz Śliwa², Zygmunt Kolenda ${ }^{1}$ \\ ${ }^{1}$ AGH University of Science and Technology, Faculty of Energy and Fuels, Al. Mickiewicza 30, 30-059 Kraków, Poland \\ ${ }^{2}$ AGH University of Science and Technology, Faculty of Drilling, Oil and Gas, Al. Mickiewicza 30, 30-059 Kraków, Poland
}

\begin{abstract}
At present many companies from the energy sector have to follow new regulations and concerns three crucial aspects of energy production: the impact on the environment, the efficiency of energy conversion and the cost of energy. From a technical point of view, the most efficient technology available today for electricity generation is based on a gas turbine combined cycle. In the present paper, an analysis of environmentally friendly, high-temperature gas nuclear reactor system coupled with gas turbine combined cycle technology has been investigated. The analysed system is one of the most advanced concepts and allow electricity generation with the higher thermal efficiency than could be offered by any currently existing nuclear power plant technology. The results show that it is possible to achieve thermal efficiency for nuclear power plant higher than $50 \%$ which is not only more than could be produced by any modern nuclear plant but it is also more than could be offered by most of the traditional power plants.
\end{abstract}

\section{Introduction}

Nuclear energy remains the most significant source of low carbon electricity production in the OECD and the second in the World [1]. Its importance as a current and future source of carbon-free energy must be recognised and should be treated on an equal footing with other lowcarbon technologies. As a proven nuclear technology can play an important role in future energy systems for electricity production in many parts of the World [2].

In $2 \mathrm{DS}\left(2^{\circ} \mathrm{C}\right)$ scenario vision [1] for nuclear energy, it is assumed that the contribution of atomic technology makes significant progress in decarbonisation of the power systems. The 2DS vision focuses primarily on new generation nuclear technologies for electricity generation. However, it takes into account the potential of other energy applications such as combined heat and power, district heating, hydrogen and other fuels production or desalination [1].

In 2014, under construction were as much as 72 reactors and this was the highest amount for almost 3 decades. However, only 3 reactors were ready to operate. It is predicted according to the 2DS scenario, that China would account for the most significant increase in nuclear capacity from $17 \mathrm{GW}$ in 2014 up to almost 250 GW until 2050 [1]. In the other countries mainly the Middle East, India, and the Russian Federation also significant increase in nuclear power capacity is predicted. It is also worth to notice that according to the 2DS scenario, nuclear capacity in most OECD countries, (except the Republic of Korea, Poland, Turkey and the UK) would decline or remain at a constant level at the same time.
In Table 1 nuclear power plant in 2018 under construction are presented accounting for different technologies: PWR (Pressurized Light-Water-Moderated and Cooled Reactor), PHWR (Pressurized Heavy-WaterModerated and Cooled Reactor) and BWR (Boiling Light-Water-Cooled and Moderated Reactor) [4].

To achieve the goal of energy sector decarbonisation and in order to limit global temperature growth to just 2 degrees Celsius by the end of the century, a halving of global energy-related emissions up to the middle of XXI century is required. This requires an unprecedented transition in the energy production and a wide range of low-carbon energy technologies is needed to support this transition, including renewable energy technologies, energy efficiency gain, carbon capture and storage units.

Table 1. Nuclear Power Plant under construction in 2018.

\begin{tabular}{|c|c|c|}
\hline $\begin{array}{c}\text { Reactor } \\
\text { Type }\end{array}$ & $\begin{array}{c}\text { Number of } \\
\text { Reactors under } \\
\text { constructions }\end{array}$ & $\begin{array}{c}\text { Total Net } \\
\text { Electrical } \\
\text { Capacity (MW }\end{array}$ \\
\hline PWR & 48 & 50680 \\
\hline PHWR & 4 & 2520 \\
\hline BWR & 4 & 5253 \\
\hline HTGR & 1 & 200 \\
\hline
\end{tabular}

In this work, an analysis of high-temperature gas nuclear reactor (HTGR) system coupled with a gas turbine (GT) and steam turbine (ST) combined cycle technology has been presented. The proposed plant system includes one of the most advanced concepts and technology available today and allows electrical energy generation with the higher thermal efficiency than could be offered by any currently existing nuclear power plant. The considered

\footnotetext{
Corresponding authors: jaszczur@agh.edu.pl
} 
system consists of the HTGR as a primary source of heat, gas turbine, the heat recovery steam generation system (HRSG) and a steam turbine with a regeneration.

\section{High-temperature nuclear reactor}

A new generation high temperature gas-cooled nuclear reactors is the most innovative concept among current advanced nuclear reactor technologies available at present [3]. The U.S. Department of Energy (DoE) developed the very high-temperature gas-cooled reactor (VHTR) with a helium coolant for advanced applications and for further expand and safe use of nuclear energy $[5,6]$. This type of reactor posses several features that distinguish them from any available or currently under work type of reactors as well as provide significant operational advantages. In HTGR the fuel is in the form of small ceramic-coated particles tri-structural isotropic fuel (TRISO) capable of operating at very high temperatures and the helium is used as a coolant $[7,8]$. For this reason, the high-temperature nuclear reactor is designed to run continuously at an outlet temperature in the range $850-900^{\circ} \mathrm{C}$. On the other hand, at the same time more advanced version of this reactor is also developed. The very high-temperature nuclear reactor able to operate with outlet temperature $900-1000^{\circ} \mathrm{C}$.

Proposed solution provides the potential for high energy conversion efficiency and allows to obtain hightemperature process heat for various applications such as cement manufacture, hydrogen production [15], petroleum refineries, desulfurization of heavy oil, chemical industry and coal gasification (see Figure 1).

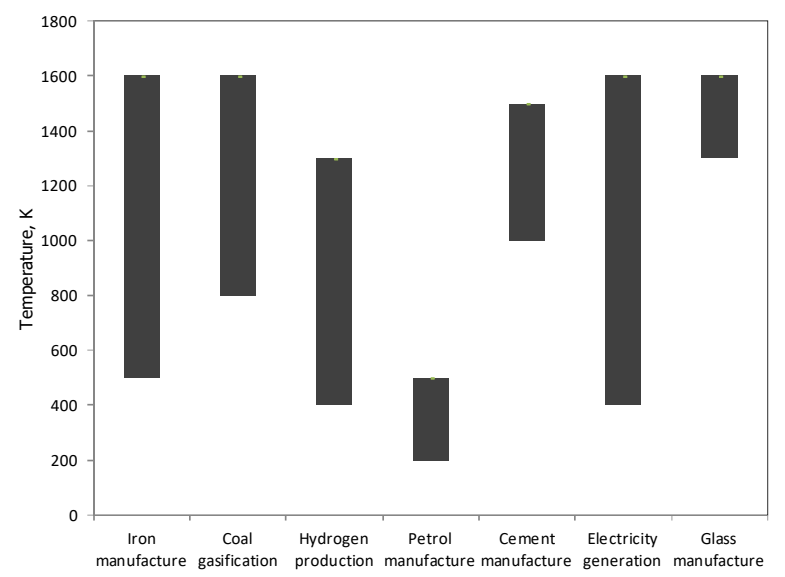

Fig. 1. Application for High-Temperature Nuclear Reactor's.

The example of selected High-Temperature Reactor's projects is shown in Table 2 .

Table 2. Examples of HTR projects.

\begin{tabular}{|l|c|c|c|}
\hline \multicolumn{1}{|c|}{ Program } & $\begin{array}{c}\text { Size } \\
\mathrm{MW}_{\text {th }}\end{array}$ & Temperature, ${ }^{\circ} \mathrm{C}$ & $\begin{array}{c}\text { Energy } \\
\text { Efficiency }\end{array}$ \\
\hline $\begin{array}{l}\text { MHTGR } \\
\text { IGT [9,10] }\end{array}$ & 200 & 850 & $48 \%$ \\
\hline $\begin{array}{l}\text { GTHTR300 } \\
{[11,12]}\end{array}$ & 600 & 850 & $45.8 \%$ \\
\hline MPBR [10] & 250 & 879 & $48 \%$ \\
\hline $\begin{array}{l}\text { GT-MHR } \\
{[7,11,13]}\end{array}$ & 600 & 850 & $>47 \%$ \\
\hline
\end{tabular}

\subsection{Gas turbine combined cycle}

The proposed gas turbine combined cycle (GTCC) employs single gas turbine (GT) and heat recovery steam generator that uses exhaust gas from a gas turbine to produce high-quality steam, which is supplied to a steam turbine (ST) [10]. In Figure 2 the advanced gas turbine combined cycle coupled with High-Temperature Nuclear Reactor and one pressure level Heat Recovery Steam Generator (1P HRSG) is presented while in Figure 3 the cycle with three pressure level Heat Recovery Steam Generator (3P HRSG) is also shown. The primary constraint in operation of the GTCC power plants is HRSG which is located directly after the gas turbine, where changes in temperature and pressure of the exhaust gases may cause significant thermal and mechanical stresses. The HRSG unit for combined cycle power plant contains three sections of heat exchanger modules for high, intermediate, and low-pressure steam respectively. In addition to that when the plant is operated in a common load-following operation mode, it can lead to sizeable thermal stress and in consequence may damage some components of the system. In order to solve this issue heat storage unit is implemented.

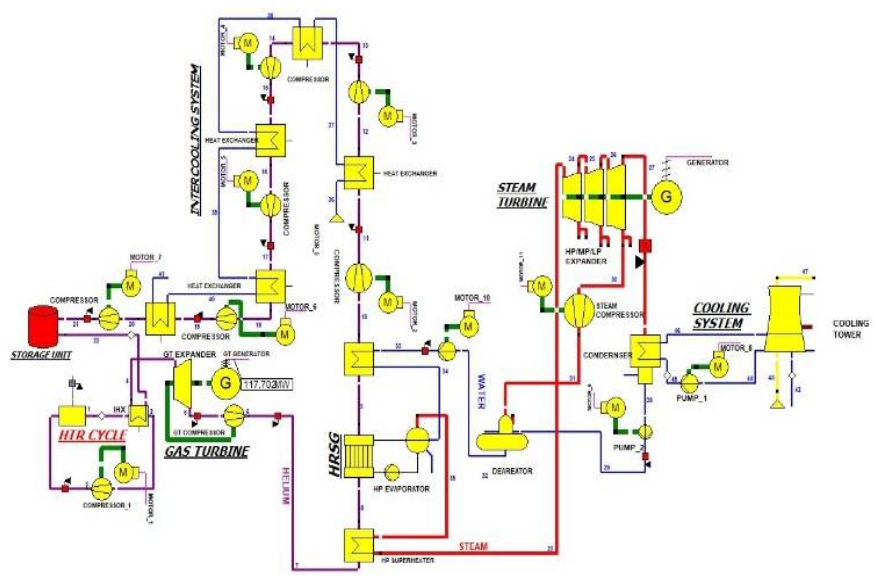

Fig. 2. Advanced Gas Turbine Combined Cycle coupled with HTR and one pressure level Heat Recovery Steam Generator.

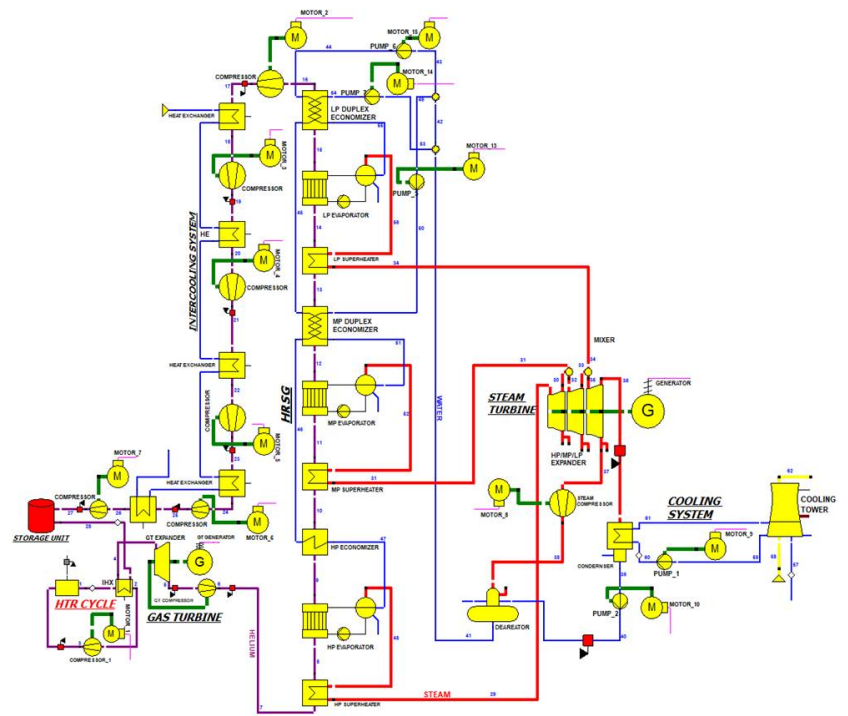

Fig. 3. Advanced Gas Turbine Combined Cycle coupled with HTR and three pressure level Heat Recovery Steam Generator. 


\subsection{Mathematical model}

A mathematical model consist of the thermodynamic equations for High-Temperature Heat Exchanger (HTHE), compressor, gas turbine, steam turbine, evaporator, deareator, pumps, condenser and cooling tower. The calculations were made using software Ebsilon software, and the details about computer modelling as well as a model equations for all key components of the high-temperature nuclear reactor coupled with the gas turbine combined cycle are presented in other the authors work [14].

The heat recovery steam generator is considered as a one of the critical components of combined cycle power plants. Any change in its design directly affects the performance of the steam cycle and therefore the performance of the combined cycle power plant. The maximum heat transfer occurs in the evaporator section for the high-pressure level, and it occurs in the economiser section for the low-pressure level.

The heat from the gas turbine exhausted gases is recovered in a Heat Recovery Steam Generator to produce steam at the required pressure and temperature. This steam is then used to provide additional electricity using steam turbines. HRSGs are classified into single, dual, and triple pressure types depending on the number of drums in the boiler. As a consequence, the thermal efficiency of a power plant strongly depends on the HRSG design.

The thermal efficiency for all presented cases has been calculated according to the following formula:

$$
\eta_{G T C C}=\frac{P_{G T}+P_{S T}-\sum_{i=1}^{n} N_{m i}}{Q_{H T R}}
$$

where: $P_{G T}$ is the gas turbine power, $P_{S T}$ is steam turbine power, and $\sum N_{m i}$ are the pumps consumption, $\mathrm{Q}_{\mathrm{HTR}}$ is the heat supplied from high-temperature nuclear reactor. Gas turbine power is given by the following equation [9]:

$$
P_{G T}=\eta_{i s} \eta_{m} \eta_{e} \eta_{m g} \dot{m}_{\text {He1 }} c p_{\text {He }}\left[T_{\text {IT }}-T_{\text {OUT }}\right]-\frac{\eta_{m} \dot{m}_{\text {He1 } 1} c p_{\text {He }}\left[T_{\text {OUT }}-T_{\text {OUT_1 } 1}\right]}{\eta_{\text {isc }}}
$$

and power of steam turbine coupled with 1P (one pressure) level Heat Recovery Steam Generator is:

$$
P_{S T}=\eta_{i s} \eta_{m} \eta_{e} \eta_{m g} \dot{m}_{s} c p_{s}\left[T_{\text {IT }}-T_{\text {ouT }}\right]-u \dot{m}_{s} c p_{s}\left[T_{u}-T_{\text {out }}\right]
$$

while for 2P (two pressure) level Heat Recovery Steam Generator) [9]:

$$
P_{S T}=\eta_{i s} \eta_{m} \eta_{e} \eta_{m g}\left(\begin{array}{l}
{\left[\begin{array}{l}
\dot{m}_{S H P} c p_{S H P}\left[T_{I T}-T_{\text {OUTHP }}\right]+ \\
\left(\dot{m}_{s H P}+\dot{m}_{S I P}\right) c p_{S I P}\left[T_{I T P P}-T_{\text {OUTLP }}\right]
\end{array}\right]} \\
-u\left(\dot{m}_{s H P}+\dot{m}_{S I P}\right) c p_{s}\left[T_{T I L P}-T_{\text {OUTLP P }}\right]
\end{array}\right)
$$

and for 3P (three pressure) level Heat Recovery Steam Generator is as follows [8]:

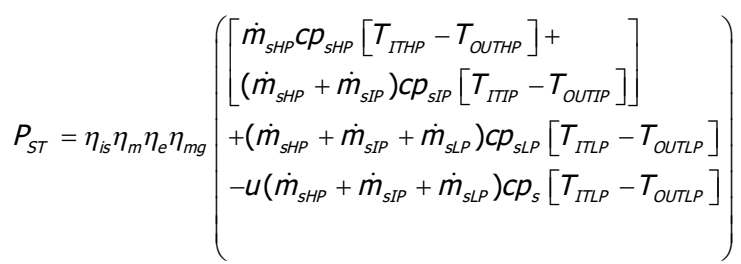

\subsection{Assumption for calculations}

The main assumptions for the thermodynamic cycle from Figure 2 and Figure 3 are shown in Table 3.

Table 3. Thermodynamic parameters used for calculation.

\begin{tabular}{|l|c|c|}
\hline \multicolumn{1}{|c|}{ Parameters } & Symbol & Value \\
\hline Thermal power & $Q_{H T R}$ & $300 \mathrm{MW}_{\mathrm{th}}$ \\
\hline Reactor outlet temperature & $T_{R O U T}$ & $850 / 900^{\circ} \mathrm{C}$ \\
\hline Reactor coolant pressure & $\mathrm{p}_{\mathrm{R}}$ & $70 \mathrm{bar}$ \\
\hline Primary loop flow rate & $\dot{m}_{\text {He }}$ & $128 \mathrm{~kg} / \mathrm{s}$ \\
\hline $\begin{array}{l}\text { Coolant pressure before Gas } \\
\text { Turbine }\end{array}$ & $P_{\text {inGT }}$ & $70 \mathrm{bar}$ \\
\hline $\begin{array}{l}\text { Coolant pressure after Gas } \\
\text { Turbine }\end{array}$ & $P_{\text {ouGT }}$ & $35 \mathrm{bar}$ \\
\hline Gas Turbine Inlet Temperature & $G_{T I T}$ & $800 / 850^{\circ} \mathrm{C}$ \\
\hline Coolant flow rate in gas cycle & $\dot{m}_{\text {He1 }}$ & $104.5 \mathrm{~kg} / \mathrm{s}$ \\
\hline Gas expander mech. efficiency & $\eta_{m}$ & $99 \%$ \\
\hline Gas expander isent. efficiency & $\eta_{i s}$ & $90 \%$ \\
\hline Steam temperature before ST & $S_{T I T}$ & $565{ }^{\circ} \mathrm{C}$ \\
\hline Steam pressure before ST & $S_{I N P}$ & $177 \mathrm{bar}$ \\
\hline Steam flow rate case1/case2 & $\dot{m}_{s}$ & $48.9 / 57.7 \mathrm{~kg} / \mathrm{s}$ \\
\hline Steam temperature after ST & & $28.96{ }^{\circ} \mathrm{C}$ \\
\hline Steam turbine mech. efficiency & $\eta_{m}$ & $99.8 \%$ \\
\hline Steam turbine isent. efficiency & $\eta_{\text {is }}$ & $88 \%$ \\
\hline Gas Turbine power generation & $P_{G T}$ & $117.7 \mathrm{MW} \mathrm{e} /$ \\
& & $6.1 \mathrm{MW}$ \\
\hline Compressor power consumption & & $65.5 / 78.3 / 83$. \\
\hline $\begin{array}{l}\text { Steam Turbine power generation } \\
\text { case1 }\end{array}$ & $P_{S T}$ & $7 \mathrm{MW}$ \\
\hline $\begin{array}{l}\text { Steam Turbine power generation } \\
\text { case2 }\end{array}$ & $P_{S T}$ & $77.4 / 91.4 / 93$. \\
\hline generator electrical efficiency & $\eta_{e}$ & 0.9856 \\
\hline
\end{tabular}

\section{Results and discussion}

The results for an analysed Gas Turbine Combined Cycle coupled with High-Temperature Nuclear Reactor are shown in Figures 4-9. One may infer from the Figure 4 that the proposed system can generate electricity with a thermal efficiency in the range $44.8-51.4 \%$ depending on the case: 1P (one pressure) and 3P (three pressure) level Heat Recovery Steam Generator.

The use of the system based on the layout of Gas Turbine Combined Cycle coupled with HighTemperature Nuclear Reactor with one pressure heat recovery steam generation system from Figure 2 can generate of about $183.23 \mathrm{MW}_{\mathrm{e}}$ of electricity (see Figure 5 and Figure 6). 


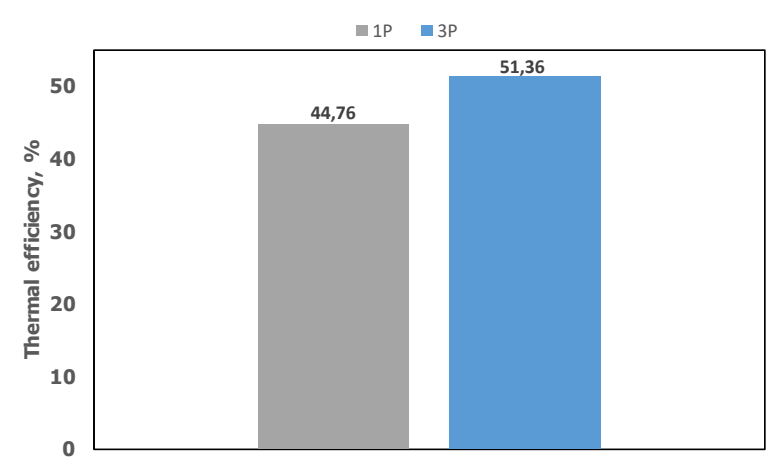

Fig. 4. The thermal efficiency for the $1 \mathrm{P}$ (one pressure) and $3 \mathrm{P}$ (three pressure) HRSG.

When the system is equipped with three pressure Heat Recovery Steam Generation, it is possible to obtain electrical power equal to $201.41 \mathrm{MW}_{\mathrm{e}}$ (see Figure 5 and Figure 6). One may obtain a significant growth in the electrical power when three pressure heat recovery steam generation unit is used.

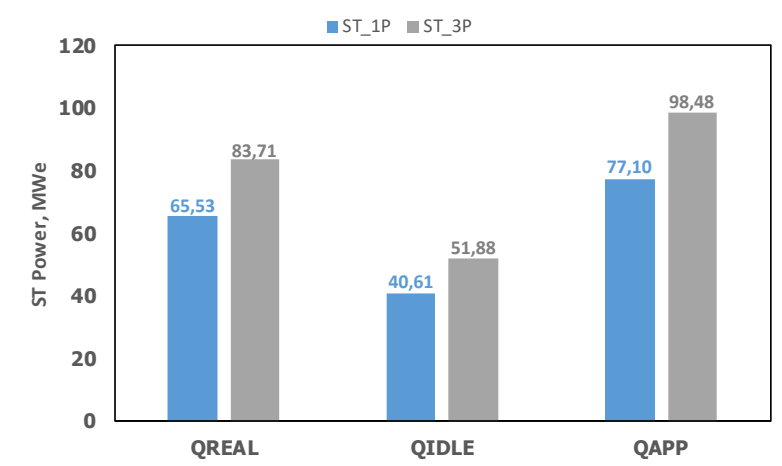

Fig. 5. The real, idle and apparent electrical power of steam turbine for the $1 \mathrm{P}$ (one pressure), and 3P (three pressure) HRSG.

The thermodynamic analysis has also been performed in order to investigate the effect of High-Temperature Nuclear Reactor temperature increase - from $800^{\circ} \mathrm{C}$ to $850^{\circ} \mathrm{C}$ - however, assuming the constant thermal power of the reactor equal to $300 \mathrm{MW}_{\text {th }}$ as well as constant temperature difference (about $50^{\circ} \mathrm{C}$ ) in the primary heat exchanger. The results of this analysis are presented in Figures 6-8.

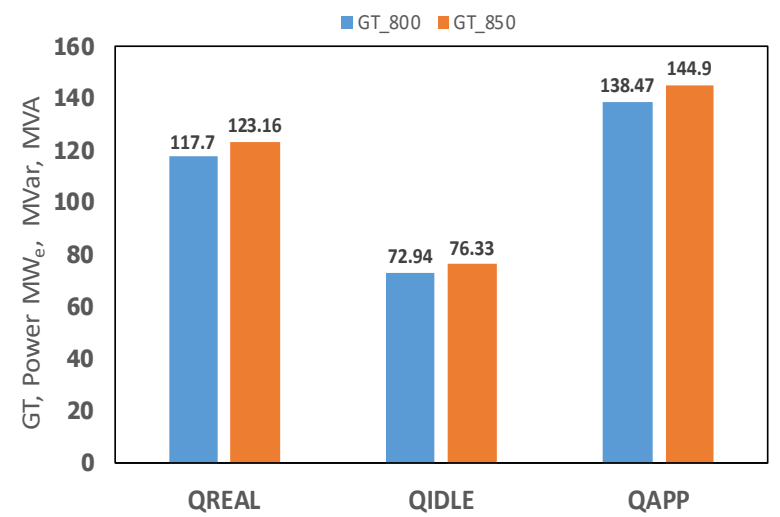

Fig. 6. The real, idle and apparent power for gas turbine and HTR output temperatures $800^{\circ} \mathrm{C}$ and $850^{\circ} \mathrm{C}$.
It is clear that the thermodynamic cycle conditions depend on High-Temperature Nuclear Reactor parameters and steam parameters delivery to Steam Turbine (SST-3000 with a constant value of inlet pressure $\mathrm{p}_{\mathrm{o}}=177$ bar and inlet temperature $\mathrm{T}_{\mathrm{o}}=565^{\circ} \mathrm{C}$ ) as well as on the cycle configuration. The influence of the High-Temperature Nuclear Reactor temperature on the real, idle and apparent electrical power of the gas turbine is presented in Figure. 6.

In Figure 7 the real, idle and apparent electrical power of the Steam Turbine for the two different nuclear reactor outlet temperatures $800^{\circ} \mathrm{C}$ and $850^{\circ} \mathrm{C}$ and for the for the $1 \mathrm{P}$ (one pressure), and 3P (three pressure) Heat Recovery Steam Generator level are shown.

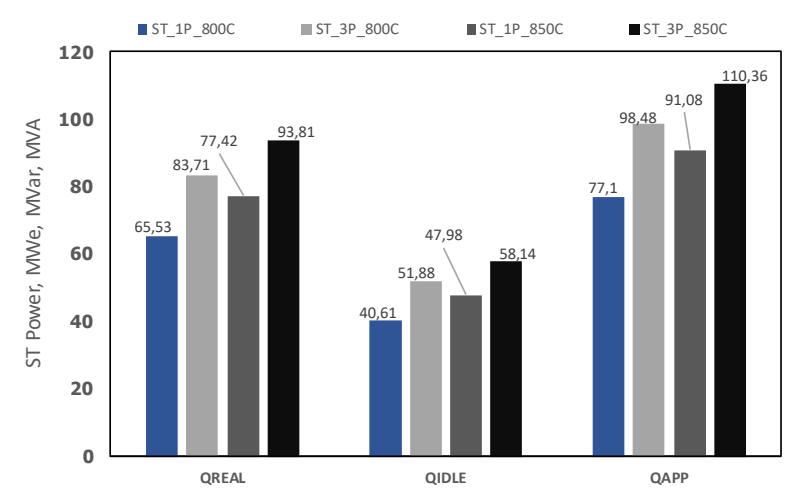

Fig. 7. The real, idle and apparent electrical power of steam turbine for cases $800^{\circ} \mathrm{C}, 850^{\circ} \mathrm{C}$ and for the $1 \mathrm{P}$ (one pressure), 3P (three pressure) HRSG levels.

The thermal efficiency for two different outlet temperatures of working fluid from High-Temperature Nuclear Reactor is shown in Figure. 8. As can be seen, the highest thermal efficiency can be observed for the system 3P (three pressure) HRSG levels system and reactor outlet temperature $800^{\circ} \mathrm{C}$ while for the system $1 \mathrm{P}$ (one pressure) HRSG system and temperature $850^{\circ} \mathrm{C}$ the efficiency is (due to reactor assumption) more than 10 percentage points lower.

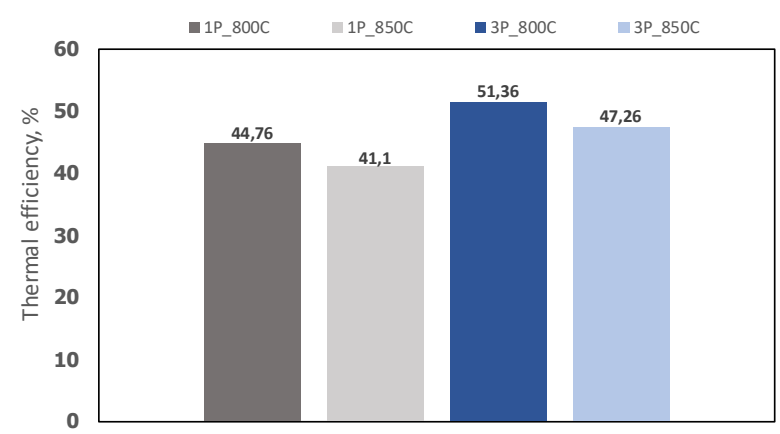

Fig. 8. The thermal efficiency comparison for the 1P (one pressure), 3P (three pressure) HRSG levels and for reactor outlet temperature $800^{\circ} \mathrm{C}, 850^{\circ} \mathrm{C}$.

The value for the main thermodynamic parameters obtained from the calculation at the key points of analysed cycle (see numbering in Figure 2 and Figure. 3) and for the $1 \mathrm{P}$ (one pressure) and 3P (three pressure) HRSG levels are presented in Table 4, and 5. 
Table 4. Thermodynamic parameters at selected points of the layout and for the reactor outlet temperature $850^{\circ} \mathrm{C}$.

\begin{tabular}{|c|c|c|c|c|c|c|c|c|}
\hline \multirow[t]{2}{*}{ Lp. } & \multicolumn{4}{|c|}{$1 P$} & \multicolumn{4}{|c|}{ 3P } \\
\hline & $\underset{\text { bar }}{\mathbf{p}}$ & $\begin{array}{c}\mathbf{t} \\
{ }^{\circ} \mathbf{C}\end{array}$ & $\underset{\mathrm{kg} / \mathrm{s}}{\mathrm{m}}$ & $\begin{array}{c}\mathrm{h} \\
\mathrm{kJ} / \mathrm{kg}\end{array}$ & $\underset{\text { bar }}{\mathbf{p}}$ & $\begin{array}{c}\mathbf{T} \\
{ }^{\circ} \mathrm{C}\end{array}$ & $\underset{\mathrm{kg} / \mathrm{s}}{\mathrm{m}}$ & $\begin{array}{c}\mathrm{h} \\
\mathrm{kJ} / \mathrm{kg}\end{array}$ \\
\hline 1 & 70 & 850 & 128 & 4414 & 70 & 850 & 128 & 4414 \\
\hline 4 & 69.5 & 800 & \multirow{5}{*}{104} & 4155 & 69.5 & 800 & \multirow{5}{*}{104} & 4155 \\
\hline 5 & 35 & 566 & & 2941 & 35 & 566 & & 2941 \\
\hline 6 & 36 & 577 & & 3000 & 36 & 577 & & 3000 \\
\hline $10 / 15$ & 35.9 & 311.2 & & 1616 & 35.7 & 206.6 & & 1072 \\
\hline $21 / 26$ & 42 & 104.8 & & 544 & 42 & 99.7 & & 517 \\
\hline $23 / 28$ & 177 & 565 & \begin{tabular}{|l|l}
48.9 \\
\end{tabular} & 3463 & 177 & 565 & 48.9 & 3463 \\
\hline 31 & - & - & - & & 100 & 444.9 & 61.78 & 3228 \\
\hline 34 & - & - & - & & 28 & 272.3 & 68.4 & 2929 \\
\hline $27 / 35$ & 0.04 & 28.9 & 42.1 & 2101 & 0.04 & 28.9 & 61.9 & 2061 \\
\hline $32 / 41$ & 1.7 & 115.1 & 48.9 & 483 & 0.5 & 81.3 & 68.4 & 340 \\
\hline
\end{tabular}

Table 5. Thermodynamic parameters at selected points of the layout and for reactor outlet temperature $900^{\circ} \mathrm{C}$.

\begin{tabular}{|c|c|c|c|c|c|c|c|c|}
\hline \multirow[t]{2}{*}{ Lp. } & \multicolumn{4}{|c|}{ 1P } & \multicolumn{4}{|c|}{ 3P } \\
\hline & $\underset{\text { bar }}{\mathbf{p}}$ & $\begin{array}{c}\mathrm{t} \\
{ }^{\circ} \mathrm{C}\end{array}$ & $\underset{\mathrm{kg} / \mathrm{s}}{\mathrm{m}}$ & $\begin{array}{c}\mathrm{h} \\
\mathrm{kJ} / \mathrm{kg}\end{array}$ & $\underset{\text { bar }}{\mathbf{p}}$ & $\begin{array}{c}t \\
{ }^{0} \mathrm{C}\end{array}$ & $\underset{\mathrm{kg} / \mathrm{s}}{\mathrm{m}}$ & $\begin{array}{c}\mathrm{h} \\
\mathrm{kJ} / \mathrm{kg}\end{array}$ \\
\hline 1 & 70 & 900 & 128 & 4673 & 70 & 900 & 128 & 4673 \\
\hline 4 & 69.5 & 850 & \multirow{5}{*}{104.5} & 4414 & 69.5 & 850 & \multirow{5}{*}{104.5} & 4414 \\
\hline 5 & 35 & 605 & & 3144 & 35 & 605 & & 3144 \\
\hline 6 & 36 & 617 & & 3205 & 36 & 617 & & 3205 \\
\hline $10 / 15$ & 35.9 & 302.4 & & 1570 & 35.7 & 206.7 & & 1072 \\
\hline $21 / 26$ & 42 & 99.7 & & 518 & 42 & 99.7 & & 517 \\
\hline $23 / 28$ & 177 & 565 & $\begin{array}{l}57.8 \\
\end{array}$ & 3463 & 177 & 565 & 57.8 & 3463 \\
\hline 31 & - & - & - & & 100 & 447.6 & 71.78 & 3235 \\
\hline 34 & - & - & - & & 28 & 276.9 & 74.67 & 2941 \\
\hline $27 / 35$ & 0.04 & 28.9 & 49.7 & 2101 & 0.04 & 28.9 & 67.6 & 2069 \\
\hline $32 / 41$ & 1.7 & 115.1 & 57.8 & 483 & 0.5 & 81.3 & 74.67 & 340 \\
\hline
\end{tabular}

\section{Conclusions}

Proposed advanced gas turbine combined cycle coupled with the High-Temperature Nuclear Reactor is a desirable alternative to traditional and even modern energy production systems. It is based on one of the most advanced technologies which give the opportunity to produce electricity as well as technological heat for industrial and thermochemical processes without emissions of toxic or greenhouse gasses to the environment and with thermal efficiency higher than a traditional coal-fired power plant or nuclear power plants.

Presented system coupled with 1P (one pressure) or 3P (three pressure) level Heat Recovery Steam Generator is able to generate electrical energy at two stages: using Gas Turbine and Steam Turbine what have a significant impact on the system efficiency and system flexibility.

An increase in the reactor outlet temperature has a significant impact on the entire cycle thermal efficiency. However, under the current assumption (constant mass flow rate and constant reactor power) when increasing reactor temperature the energy efficiency conversion for the $(1 \mathrm{P}, 3 \mathrm{P})$ system is not growing due to the higher energy demand by the compressor.

\section{Acknowledgement}

The authors sincerely acknowledge financial support to the Polish Ministry of Science (Grant AGH No. 15.11.210.437 and Grant AGH No.11.11.210.312) and project GEMINI.

\section{References}

1. N. Energy, Technology Roadmap, Springer Reference (2015)

2. International Energy Agency, Energy Technology Perspectives, Int. Energy Agency, 412 (2015)

3. M. Dudek, Z. Kolenda, M. Jaszczur, W. Stanek, J. Energy Resour. Technol. 140, 20910 (2018)

4. IAEA, Reference data series, nuclear power reactors in the world, 2, 88 (2017)

5. A. C. Kadak, The Status of the US HighTemperature Gas Reactors, Eng. 2, 119 (2016)

6. A. Bredimas, Nucl. Eng. Des. 271, 41 (2014)

7. IAEA, High Temperature Gas Cooled Reactor Fuels and Materials, IAEA (2010).

8. K. Kok, Nuclear Engineering Handbook, (2009)

9. Z. Zhang, Y. Dong, F. Zhengming, Z. H. Wang, et al., Eng. 2, 112 (2016)

10. O. Olumayegun, M. Wang, and G. Kelsall, Fuel, 180, 694 (2016)

11. C. F. McDonald, Appl. Therm. Eng. 73, 80 (2014)

12. G. Locatelli, M. Mancini, N. Todeschini, Energy Policy, 61, 1503 (2013)

13. V. Zare, M. Hasanzadeh, Energy Convers. Manag. 128, 227 (2016).

14. M. Dudek, M. Jaszczur, Q. Hassan, Z. Kolenda, Int. Conf. on Computational Heat, Mass and Momentum Transfer, Kraków, 2018.

15. I. Gutowska, Study on depressurized loss of coolant accident and its mitigation method framework at very high temperature gas cooled reactor, Oregon State University, Ph.D. thesis, (2015) 